\title{
Preobesity has High Cardiovascular Risks and soon could be a Disease
}

\author{
Gopal Krushna Pal*, Jagadeeswaran Indumathy
}

\section{Gopal Krushna Pal ${ }^{1 *}$, Jagadeeswaran Indumathy ${ }^{2}$}

'Department of Physiology, Jawaharlal Institute of Postgraduate Medical Education and Research, Puducherry, INDIA.

${ }^{2}$ Department of Biological Sciences, Southern Methodist University, Dallas, Texas.

\section{Correspondence}

Prof. Gopal Krushna Pal Editor-in-Chief, IJCEP, Department of Physiology, Jawaharlal Institute of Postgraduate Medical Education and Research, Puducherry, INDIA.

Phone: +91-9344291160

Email: drgkpa|@gmail.com

\section{History}

- Submission Date: 22-08-2019;

- Review completed: 05-09-2019;

- Accepted Date: 20-09-2019.

DOI : 10.5530/ijcep.2019.6.3.21

\section{Copyright}

(c) 2019 Phcog.Net. This is an openaccess article distributed under the terms of the Creative Commons Attribution 4.0 International license.
Recently, India has emerged substantially in economy, growth and development and occupies the position of world's seventh largest economy. Due to rapid economic growth, the lifestyle of the general Indian population has changed greatly. Increased job opportunities and increased income of the family has made a larger section of the public rich and in general, the people have enough money. There is rapid proliferation of hotel industries everywhere and there are restaurants of kinds at all places. With access to all varieties of food and having money to pay for enough eating, the country which was starving a decade before has now become the country of plenty and excess eating. Also, recently the use of two-wheelers and cars has increased in the community that has significantly resulted in reduction in physical activity such as walking and cycling. All these factors have contributed to obesity and overweight, the conditions of excess adiposity (more fat deposition in the body). However, also there is simultaneous increase in health consciousness due to increased incidence of diabetes and related complications, for which people have been motivated to do some kind of physical exercises such as morning walk, going to gym etc. Therefore, the incidence of gross obesity has been reduced in the population. However, due to faulty eating habit and lack of physical activities at work place, a larger population has increase in body weight, though overtly they do not look obese. This is called overweight. In this state of overweight, recently it has been observed to have many health problems, especially the future risks of developing diseases, particularly the cardiovascular (CV) diseases. ${ }^{[1]}$ Especially, overweight people in Indian subcontinent are seen to be more prone to $\mathrm{CV}$ risks. Therefore, range of Body Mass Index (BMI) for overweight Indians and Asians in general is currently much lower (BMI 23-27.5) compared to the population in western countries (BMI 25-29.9). ${ }^{[2]}$ The prevalence of diabetes, hypertension, heart disease and related complications such stroke has been observed to be quite high and comparable to the prevalence that is seen obesity, especially in Indian population. ${ }^{[3]}$ Therefore, the term 'Overweight' has recently been renamed as 'Pre-obesity'. Preobesity similar to that of prehypertension and prediabetes is reported to be a condition of greater health concern.

The risk of developing diabetes and hypertension is very high in preobesity. The risk of developing heart failure goes up $11 \%$ for every one-point increase in
BMI. It has been observed that decrease in body weight reduces the risk of developing heart failure in a wide of variety of clinical spectrum. However, additional research is warranted to ascertain whether intentional weight reduction to optimal levels in overweight and obese individuals, together with improved physical activity, would lessen the probability of heart failure. The Framingham Heart Study suggests that men and women who are overweight without necessarily being obese can have a significant heart-failure risk and that "perhaps a BMI $<25 \mathrm{~kg} / \mathrm{m}^{2}$ represents an optimal goal for the primary prevention of heart failure". ${ }^{[1,4]}$ The BMI is an easy and standard method of assessing adiposity (fatness). ${ }^{[5]}$ The BMI ranges for preobesity (overweight) and obesity are calculated based on the results of various multicentric previous studies on the effect of excessive body fat on health, diseases and death that are reasonably well related to adiposity. BMI was developed as a risk indicator of diseases, as increase in BMI is correlated with the risk for occurrence of some common conditions related to overweight and obesity that include premature death, cardiovascular diseases, high blood pressure, osteoarthritis, some cancers and diabetes. ${ }^{[6]}$ Therefore, BMI of vulnerable population in the community should be measured regularly, may be at least once in six months to encourage them adopt to healthy lifestyle with the primary objective to prevent development of preobesity and obesity and their related morbidities and mortalities.

\section{REFERENCES}

1. Samaras K, Tevaearai H, Goldman M, Coutre JL, Holly JMP. Editorial: With Obesity Becoming the New Normal What Should We Do?. Front Endocrinol. 2019;10:250.

2. WHO expert consultation. Appropriate body-mass index for Asian populations and its implications for policy and intervention strategies. Lancet. 2004;363(9403):157-63.

3. Indumathy J, Pal GK, Pal P. Vagal withdrawal is similar in preobese and obese Indian adults. Int J Clin Exp Physiol. 2015;2(4):239-41.

4. Indumathy J, Pal GK, Pal P, Ananthanarayanan PH, Parija SC, Balachander J, et al. Decreased baroreflex sensitivity is linked to sympathovagal imbalance, body fat mass and altered cardiometabolic profile in pre-obesity and obesity. Metabolism Clinical and Experimental. 2015;64(12):1704-14.

5. Indumathy J, Pal GK, Pal P, Ananthanarayanan PH, Parija SC, Balachander J, et al. Association of sympathovagal imbalance with obesity indices and abnormal metabolic biomarkers and cardiovascular parameters. Obesity Research and Clinical Practice. 2015;9(1):55-66.

6. Indumathy J, Pal P, Pal GK, Dutta TK. Assessment of heart rate variability indices in overweight and obese Indian population. Int J Clin Exp Physiol. 2014;1(3):192-5

Cite this article: Pal GK, Indumathy J. Preobesity has High Cardiovascular Risks and soon could be a Disease. Int J Clin Exp Physiol. 2019;6(3):77. 